\title{
DISSERTATION ABSTRACTS
}

Akina, William Keli'i. Ph.D. University of Hawai'i at Manoa, 2010. Classical Confucianism as a Vision for the Exemplary Treatment of PersonsA Contribution to the East-West Discourse on Human Rights. UnM: AAT 3448630.

Classical Confucianism, through its repository of canonical texts, offers a compelling vision for the exemplary treatment of persons that is ancient in origin, relevant to the needs of present-day China, and contributory to future East-West discourse on human rights. The first of two independent prongs in this dissertation argues that Classical Confucianism generates a foundation for cultivating human creativity and excellence. Imbedded within a picture of the ideal functioning society in the $D a$ $X u e$, (conventionally translated "Great Learning") and explicated as exemplary personhood (junzi) within the Lun Yu (the "Analects") are the rudiments for a universal, normative standard of exemplary treatment of all members of society. The metaphysical roots for this standard are presumed by Classical Confucian literature such as the Shujing ("Book of History") and most notably the Yijing ("Book of Changes") in which principles such as the harmonization and creativity of nature are understood also as human processes which society is called to cultivate within all individuals. Through the application of Onto-hermeneutics (a hermeneutical method developed by Professor Chung-ying Cheng) to the relevant texts, the concept Tianming as moral authority (conventionally, Mandate of Heaven), emerges as the universal, normative standard for the exemplary treatment of persons. The effective implementation of the Classical Confucian vision, resulting in such widespread personal cultivation at the level of self-actualization (as in Abraham Maslow's hierarchy of needs), entails the prior satisfaction of lower order human needs.

The second-prong of this dissertation examines the notion of human rights within the Western liberal democratic tradition (i.e., Hobbes, Locke, Rousseau, et al.) and considers the analysis of rights by Wesley Hohfeld and conceptions of justice by John Rawls. As a work in comparative philosophy, this dissertation argues that the virtues and duties in Classical Confucianism implicitly generate the standard of universal

\footnotetext{
* Compiled by Margaret Wee-siang Ng.
} 
humane treatment of persons sought after in the liberal democratic (i.e., social contractarian) tradition. A definition of human rights is offered in which the content of rights is differentiated from the mechanism of rights, thereby providing a framework for recognizing comparable outcomes (i.e., the content of rights) between two otherwise incommensurable systems (i.e., incommensurable at the level of mechanism). This analysis makes possible the translation of virtues-duties language into claim-rights language, yielding a set of comparable foundational concepts for an East-West approach to human rights. It is the author's conviction that China, by drawing upon its rich philosophical heritage, is in a position to offer the world a system of values for the exemplary treatment of persons, contributory to the human rights discourse.

Berthel, Kenneth. Ph.D. University of California, Irvine, 2010. Zhiyin 知音 and Zhiyan 知言, Knowing Notes and Knowing Words: Aurality and Reality in Ancient China. UnM: AAT 3422114.

This dissertation focuses on the philosophies of language and music of three Warring States philosophers-Mo Zi, Zhuang Zi, and Xun Ziwho represent the "final" word from the period for the major traditions that would come to be known as Mohism, Daoism, and Confucianism, respectively. Additionally, there is a chapter dedicated to the period philosophy of music in general, with a study of the contents of the Yue $J i$ (Record of Music). The primary aim is not an effort to understand the mechanics of each school's philosophy of language or music per sethough this is an important fundamental, of course-but rather to draw conclusions about the underlying cosmological commitments that can be inferred from the positions on language that each thinker carves out. Each thinker's position on the problem of language will be taken as revealing his cosmological perspectives, and the thesis gleans conclusions about the architecture of their cosmos (which none of these thinkers explicitly provides) from theories that are explicitly about language or music. The dialectic between the stated theories on aural phenomena and those on other areas of philosophy, such as ontology, epistemology, and ethical concerns, advance our understanding of all facets of each of these rich schools of thought, particularly by shedding light on precisely what sort of universal structure each of these conceived of their systems as operating within. 
Brackenridge, J. Scot. Ph.D. The University of Wisconsin-Madison, 2010. The Character of Wei-Jin Qingtan: Reading Guo Xiang's "Zhuang Zi" Commentary as an Expression of Political Practice. UnM: AAT 3448864.

This dissertation seeks to understand Guo Xiang's (d. 312 C.E.) commentary to the Zhuang Zi not only in the more familiar contexts of Taoism and Chinese philosophy, but also in the light of the society in which he lived. The socio-historical circumstances and political practices of the Wei-Jin period (220-420) created a motivation to produce classical commentary, and figures like Guo Xiang often pursued high government office on the strength of their reputations as exegetes. I offer a historical reconstruction of qingtan ("pure discussion"), a rhetorical tradition of character evaluation that was instrumental in advancing political careers. In light of this practice, I give a literary reading of Guo Xiang's commentary that goes beyond the standard philosophical treatment of his work. When we look more closely at Guo's analysis in the Zhuang Zi commentary, we can see the currents of contemporary political thought that inform his work, a factor that may explain why it was so well received. In addition, a more grounded understanding of qingtan opens up the study of other influences in the Wei-Jin intellectual environment, including newly translated Mahayana Buddhist sutras.

I analyze six key topics in Guo Xiang's commentary usually taken to be "misreadings" of the Zhuang Zi text, or as "impositions of Ruist values," and argue that these may be better read as expressions of qingtan institutional ideology. I conclude that taking into account the political dimension of qingtan debate makes new contributions to the study of Wei-Jin thought more generally, and opens new vistas on the problem of how to apply the labels "Ruist," "Daoist," and "Buddhist" in the context of early medieval China.

Chan, Wing Nam Joyce. Ph.D. The Ohio State University, 2011.

Craniofacial Differences Between Modern and Archaeological Asian Skeletal Populations. UnM: AAT: 3477001.

The principal objective of this study is to perform a biological distance analysis of two Asian ethnic groups to better understand environmental factors influencing cranial shape and size. Cranial shape and size are influenced by both epigenetic and genetic factors, resulting in differences in crania over time. Cranial measurements can be used as a proxy for genetic data and to understand epigenetic factors affecting crania. Therefore, craniometrics can be used to determine differences between populations.

Ancient and modern Chinese and Thai skeletal populations were used for this biological distance analysis. The ancient Chinese population 
is from northern China at Anyang dating to the Shang Dynasty ( 1600 в.с. -1046 в.с.) while its modern counterpart is located in Hong Kong dating from $1977-83$. Individuals from both populations are thought to have belonged to the Han ethnic group and are possibly biologically related. Both Thai populations are located in northeastern Thailand, known as the Isaan region. The ancient Thai population from the Ban Chiang site is dated through the Pre-metal to Iron Age periods (2000 B.C.-200 A.D.) while the modern population dates from 1970s to present. Data were collected on crania at 29 anthropologically accepted measurements to explore epigenetic and biological relationships between modern and ancient populations. Data were subjected to multiple multivariate statistical tests to understand causative agents for change and differences between populations.

These results suggest that modern and ancient Thai and Chinese populations have markedly different crania, especially in shape. However, correlated factors could not be identified in this study, primarily due to lack of historical data. Geographical, temporal, and climate variables such as temperature were tested against measures of biological distance with little to no correlation discovered. Interestingly, modern and ancient Chinese populations displayed the closest biological affinity, possibly due to similar environments and lack of genetic changes. Ban Chiang individuals were the most biologically distant from other populations, indicating possible genetic differences not yet understood. These genetic differences could indicate either that Ban Chiang individuals are not recently ancestral to the modern Thai population or that a mass migration movement into northeast Thailand had occurred.

These results are interpreted to indicate that environmental factors have played a large role in altering cranial shape in these two ethnically Asian populations since genetic alteration in the areas has not been documented. Environmental factors have caused isometric changes in cranial shape as crania have become distinct from their ancestral counterparts. Cultural changes, such as diet shifts and modernization, are possible causative agents for these changes witnessed in these populations.

The findings of this study contribute to our understanding of human cranial variation for these two Asian groups, and to broader discussions of epigenetic and genetic relationships in the expression of cranial morphology. This research also contributes to the discussions of how biological distance in the crania has been influenced by epigenetic factors and ultimately how the peopling of modern Asia occurred. 
Harkness, Ethan Richard. Ph.D. The University of Chicago, 2011. Cosmology and the Quotidian: Day Books in Early China. UnM: AAT 3487616.

The aim of this dissertation is to identify and contextualize important features of the archaeologically-recovered early Chinese manuscript genre known as rishu ("day books"). Dating from the period between the late fourth century and the late first century в.с., these texts circulated widely among local elites, who used them to determine auspicious times and places for the affairs of daily life. Through inductive analysis of the second century в.c. day-book manuscript found at Kongjiapo in Suizhou, Hubei in 1992, I consider the social circumstances of day-book compilation and usage, editorial conventions in manuscript production, and the implied cosmology underlying the various systems by which day books assigned auspicious or inauspicious qualities to times and directions. Close attention is given to the final 21 slips of the Kongjiapo day-book manuscript, a cosmological text called "Sui" ("Year"). This text is shown both to broaden our current conception of the early Chinese genre of yue ling ("monthly ordinances") and to embody connections with other types of technical literature such as the well-known classic of Chinese medicine Huangdi neijing. These results in turn bring a significant new critical perspective to the reading of transmitted classics of technical literature such as Huainanzi.

Hung Ling-yu. Ph.D. Washington University in St. Louis, 2011. Pottery Production, Mortuary Practice, and Social Complexity in the Majiayao Culture, NW China (ca. 5300-400o BP). UnM: AAT 3489973.

The Majiayao Culture (ca. 5300-400o BP) is famous for its stunning painted pottery vessels. First discovered in the 1920s in northwestern China, these Neolithic painted pottery vessels have become one of the most popular icons used to depict the rich material culture of ancient China. Today, many museums throughout the world hold Majiayao painted pottery vessels in their collections. We know much about the pottery, but research on the associated Majiayao Culture has been limited to cultural histories that emphasize chronology and trait-list classification. These approaches present the Majiayao Culture as static and simplify the social and economic complexity of the people who composed this society. Although scholars commonly assume that Majiayao painted pottery vessels were made by specialized craftspeople, the social and economic processes behind the production of these vessels have long been overlooked.

Materials discussed in this dissertation include firsthand attribute and physicochemical analyses of hundreds of ceramic vessels and samples 
selected from multiple sites in Gansu, Qinghai, and Sichuan provinces. These data are supplemented with settlement pattern and mortuary analyses of thousands of published sites and burials. By synthesizing these data, this study illustrates a positive correlation between regional density of settlement distribution, intensification of pottery production, and degree of social inequality in each phase during the Majiayao Cultural period. Rather than showing a simple linear process of social complexity, however, there are distinct regional variations in each phase and significant regional fluctuations over time. Results of this study demonstrate that economic and social patterns related to Majiayao ceramics were far more complex than we have previously thought.

Specifically, intensive ceramic production among these Neolithic agricultural communities was primarily driven by the increasing demand to offer large quantities of painted pottery vessels at funerals. These Neolithic communities fulfilled the increasing demand for painted pottery vessels in mortuary practices by sacrificing vessel quality to promote production efficiency. When the demand for vessel quantity reached its peak, no products were made with the skill and care comparable to the most high-quality vessels dated to earlier phases. Further, the great demand also encouraged the development of inter-regional exchange involving painted pottery vessels. Certain production groups in the core area of site distribution in each phase were able to make relatively high quality vessels and successfully increased their output to best meet the needs of both internal and external consumers. Therefore, I argue that the distribution and consumption of these craft goods was not limited by kin organization. I emphasize that these vessels were marketable objects-commodities. The way these craft goods moved from the hands of potters to the consumers was associated with complicated social and economic interaction/exchange, about which we still have limited understanding.

The development of social hierarchy in this region is indicated by the disparity of painted vessels unearthed from graves. The preference for painted storage jars may relate to the development of agriculture in this region. These vessels seem to be used as a symbol of wealth. However, these craft goods were generally available for most social members of different ranks. Exchange of goods also led to an exchange of cultural and social experiences. Diverse social values might have been delivered and structured through the circulation of Majiayao painted pottery vessels among the living and between the living and the dead. Patterns identified in this study shed new insights into conceptualizing the dynamic social and economic relationships among Neolithic villagescale communities. 
Kory, Stephan N. Ph.D. Indiana University, 2012.

Cracking to Divine: Pyro-Plastromancy as an Archetypal and Common Mantic and Religious Practice in Han and Medieval China. UnM: AAT 3543218.

Pyro-plastromancy, the mantic art of cracking turtle plastrons with fire, is one of the earliest documented forms of divination in East Asian history. This dissertation springs from the simple thesis that the divinatory cracking of turtle plastrons remained a living mantic and religious tradition in first-millennium c.E. China. Theoretical insights from the modern academic fields of semiotic, literary, cultural, and religious studies are utilized to help construct a multi-dimensional approach able to account for the methods, functions, institutions, and theories associated with the technique. These dimensions are separately and diachronically analyzed in the body of the dissertation to set up a number of brief comparative and synchronic views of pyro-plastromancy set in more circumscribed Han and medieval Chinese milieus.

Pyro-plastromancy is not just any form of Chinese divination; it is the archetypal model, as reflected in the pervasive use of the pyro-osteomantic (divination with fire and bone) and pyro-plastromantic term $b u$ for all divination. As the historically earliest form of royal divination, the divinatory cracking of bones and shells possessed a special political and religious authority as the high orthodox form of divination, even when much cheaper and hence popularly accessible arts like achilleomancy (divination with yarrow stalks) and hemerology (the determination of auspicious dates) became dominant. For academic purposes, the study of a semi-ossified form of orthodox divination is an ideal place to attempt a truly multi-dimensional analysis, because while all the features of a developed and socially sanctioned mantic activity were present, its scope and evolution was relatively limited.

This dissertation concludes that the divinatory cracking of turtle plastrons persisted as a potent source of cultural capital, served as a focal point of institutional and popular mantic and religious interaction, and flourished as an archetypal and common way to access culturally constructed notions of divine or spiritual power in Han and medieval China.

Laursen, Sarah. Ph.D.University of Pennsylvania, 2011.

Leaves That Sway: Gold Xianbei Cap Ornaments from Northeast China. UnM: AAT 3463014.

Over the last fifty years, rich finds of gold objects have been uncovered in China's northeastern Liaoning province. These tombs belonged to a tribe of steppe nomads called the Murong Xianbei, who settled north of the Great Wall during the Han dynasty and established a succession of 
short-lived states called Yan that ruled parts of Northeast Asia during the third to fifth centuries C.E. Until now, scholarship on the history of the Murong and the rapidly emerging field of Murong archaeology has been published almost exclusively in Chinese. This dissertation seeks to rectify the lack of Western scholarship about this unique border population and their cultural identity as expressed though gold personal adornments.

The gold objects in Murong tombs are typically decorated with some combination of openwork and pendant gold leaves attached by wires, some taking the form of trees or antlers. These were probably affixed to fabric caps and have been associated with ornaments described in the Chinese histories as buyao ("step-sway") ornaments because their thin sheet gold leaves tremble and sway with each step the wearer takes. However, leaf-covered gold crowns and headdresses excavated from tombs across Central Asia, Western Asia, and the Mediterranean have also been proposed as prototypes. This dissertation considers the existing textual and visual data supporting arguments for local and western origins and arrives at new conclusions concerning the relationships between Murong artisans and their counterparts in China, Central Asia, and the Near East though the careful study of the visible traces of the manufacturing process.

Lee Yong-Yun. Ph.D. The University of Wisconsin Madison, 2011. The Ethical Mapping of Tian (Heaven) and Dao (Way): An Interaction Between Cosmology and Ethics in Early China. UnM: AAT 3501263.

My dissertation focuses on the use of two terms Tian (Heaven) and Dao (Way) to examine the mutual interaction between cosmology and ethics in early Chinese texts. In doing this, I take to heart the assumptions behind the idea of the hermeneutic circle: namely, that we cannot really understand any part of a text until we understand the whole (and vice versa). Through this approach, I attempt to show that there is a structural resemblance between the cosmological and ethical claims put forward in early Chinese texts, in the sense that both sets of claims emerge from and reflect a shared hierarchical framework.

One noteworthy feature of the ethical teachings derived from Tian and Dao, the highest entities in the early Chinese cosmological framework, is that the teachings are typically advanced and advocated as being manifestations of some type of "natural law." However, while each of the texts I consider seeks in various ways to clothe its prescriptions for ethical behavior in the guise of "natural law," the "natural" behaviors that each sets forward as ethically desirable differ considerably, due in no small part to differences in the texts' compositors' broader understanding of nature's characteristics. Kongzi and Mengzi, for example, both under- 
stand the natural law derived from Tian as having a vertical hierarchy while Laozi and Zhuangzi regard the natural law which accords most closely with Dao as having a horizontal hierarchy.

In short, the primary goal of this dissertation has not been to evaluate (or even consider) the accuracy of any text's teachings about the structure of the universe or what it considers to be the natural order of things in light of our modern understanding of ecology or the physical sciences, but to examine how the nexus between cosmological structures and ethical mandates might be understood in relation to each other as mutually-determined components of a text's total system. Since no previous scholarship has systematically analyzed how the core philosophical terms Tian and Dao in early Chinese texts reveal structural resemblances between cosmology and ethics, this effort represents something of a pioneering attempt.

Miller, Allison Ruth. Ph.D. Harvard University, 2011.

Patronage, Politics, and the Emergence of Rock-Cut Tombs in Early Han China. UnM: AAT 3462661.

For the past thirty years, scholars have largely assumed that the ancient Chinese primarily built tombs for reasons related to the afterlife. Nearly all early Chinese tombs, whether belonging to emperors or petty local officials, are interpreted in this light-as spaces to be inhabited by the deceased after death. This focus on the afterlife, however, is a relatively recent direction in scholarship. Prior to the last few decades, Chinese scholars generally agreed that the ancient Chinese did not have a clear notion of the afterlife until the rise of Buddhism, basing their interpretation on the notorious silence of ancient texts on this issue.

This dissertation explores reasons other than the afterlife that so much wealth and labor were expended on monumental tombs in early China. It does so by analyzing the social and political tensions underlying a major shift in tomb architecture that occurred in the Western Han dynasty - the emergence of rock-cut tombs. Rock-cut tombs were meticulously-carved, grotto palaces that bore little resemblance to the mounded, earthen pit tombs that had preceded them. These tombs changed the orientation of elite Chinese burials for the rest of Chinese history.

By examining this shift in tomb architecture, my work suggests that by the mid-Western Han, tomb architecture had become a principal means by which rulers marketed new political agendas and elites expressed their social and political identities. Relying on evidence from texts and archaeology, my research traces the history of tomb construction back to the Eastern Zhou to understand why tombs may have assumed this function by the Western Han. It also demonstrates the way that the study of 
shifts in material culture can lead to significant revisions of Han political history. This study, for example, challenges the typical conflation of the reigns of Emperors Wen (r. 180-157 в.с.) and Jing (r. 157-141 в.с.), and argues that Emperor Wen, rather than the founding emperor, ought to be considered as the chief architect of Han political ideology.

O'Neill, Timothy Michael. Ph.D. University of Washington, 2010. Harbinger of Sequestered Intent: Language Theory and the Author in Traditional Chinese discourse. UnM: AAT 3421883.

The dissertation begins by exploring specific issues in the history of Western philosophy, in particular the theory of language that underlies speculation about the possibility of ideographic writing. Starting with the China Illustrata of Athanasius Kircher, the first chapter proceeds to archaeo-historically excavate Kircher's language-theoretical sources and influences ultimately reaching all the way back to the intellectualhistorical origins of ideography in the texts of Aristotle and Plato. The second chapter examines traditional Chinese discussions of language (including the origin and function of writing), focusing on two ancient dictionaries: the Erya and the Shuowen jiezi. This chapter explains just how different pre-modern Chinese language theory is from Western ideographic speculation including the stark contrast between the Erya and such works as Peter Mark Roget's eponymous Thesaurus of English Words and Phrases. The vast difference between the two, simply stated, is that traditional Chinese theory requires quotidian human intent and concrete socio-historical embeddedness for linguistic meaning to function, whereas traditional Western theory requires reified, universal, transhistorical, perhaps even extraterrestrial Forms (eide, ideai) - what Derrida and others have called the "transcendental signifieds." The third chapter carries these language-theoretical issues to an examination of the work of the scribe Sima Qian (145-87 в.C.E.), who laid the cornerstone of author-theory in China. Forcibly castrated by the emperor for a crime he did not commit, consumed by humiliation and rage, Sima Qian proceeded to compile the monumental 130 chapter Records of the Scribe, one of the most sophisticated and politically provocative documents in the history of Chinese letters, a text that ended up serving as the model for all subsequent historiography as well as biographical and autobiographical writing, prose fiction, and even much literary theory and criticism. The larger implication of the dissertation is that a better understanding of the differences in how the Chinese and Western traditions have discussed language, particularly how linguistic meaning functions, may well help to lead contemporary (posthumanist) theory to a more nuanced and culturally inclusive view of authorial intention. 
Tse, Wai Kit Wicky. Ph.D. University of Pennsylvania, 2012.

Dynamics of Disintegration: The later Han Empire (25-220 C.E.) and its Northwestern Frontier. UnM: AAT 3542908.

As a frontier region of the Qin-Han (221 B.C.E.-220 C.E.) empire, the northwest was a new territory to the Chinese realm. Until Later Han (25-220 C.E.) times, some portions of the northwestern region had only been part of imperial soil for one hundred years. Its coalescence into the Chinese empire was a product of long-term expansion and conquest, which arguably defined the region's military nature. Furthermore, in the harsh natural environment of the region, only tough people could survive, and unsurprisingly, the region fostered vigorous warriors. Mixed culture and multi-ethnicity featured prominently in this highly militarized frontier society, which contrasted sharply with the imperial center that promoted unified cultural values and stood in the way of a greater degree of transregional integration. As this project shows, it was the northwesterners who went through a process of political peripheralization during Later Han times, played a harbinger role of the disintegration of the empire, and eventually led to the breakdown of the early imperial system in Chinese history.

In this study, the author adopts a regional perspective by focusing on the role of the northwestern frontier region vis-à-vis the imperial center to explain the collapse of the Later Han empire. The author emphasizes the role that regional conflicts played in the decline and fall of the dynasty, and pays particular attention to the incompatibility between the militarized culture of the northwest and the civil values promoted by the imperial center, which was dominated by the eastern-based scholarofficials. Through this analysis, the author provides a case study of the relationship between the imperial center and the regions with different cultures and identities, and the variations of the conception of such relationships in the period of early imperial China.

Vogt, Paul Nicholas. Ph.D. Columbia University, 2012.

Between Kin and King: Social Aspects of Western Zhou Ritual. UnM: AAT 3518738 .

The Western Zhou period (ca. 1045-771 B.C.E.) saw the dissemination of a particular style of ancestral ritual across North China, as the Zhou royal faction leveraged its familiarity with the ritual techniques of the conquered Shang culture to complement its project of state formation. Looking back on this era as the golden age of governance, Eastern Zhou and Han thinkers sought to codify its ritual in comprehensive textual treatments collectively known as the Sanli and, in particular, the Zhouli, 
or "Rites of Zhou." Later scholarship has consistently drawn on the Sanli as a reference point and assumed standard for the characterization of Western Zhou rites. Current understandings of the formative era of early Chinese ritual are thus informed by the syncretic and classicizing tendencies of the early empires.

To redress this issue, the present study explores the ritual practices of the Western Zhou based on their records on inscribed bronzes, the most extensive source of textual information on the period. It characterizes Western Zhou ancestral rites as fluid phenomena subject to continued redefinition, adoption, cooption, and abandonment as warranted by the different interests of Western Zhou elites. Separate discussions consider the role of ancestral rites and inscribed bronzes in materializing the royal presence within the interaction spheres of elite lineages; the evolution of ritual performances of Zhou kingship, and their relationship to the military and political circumstances of the royal house; the emergence of new ritual contexts of patronage, recognition, and reward that differentiated between members of expanding lineages and intensified royal control over key resources; and the combination of multiple ritual techniques with royal hospitality provision to create major ritual event assemblies. A final synthesis brings these discussions together into a sequential analysis of Western Zhou ritual, relating them to the evolving political situation of the Zhou royal house.

Zhang Hanmo. Ph.D. University of California, Los Angeles, 2012. Models of Authorship and Text-making in Early China. UnM: AAT 3540361.

This dissertation aims to show how the author functioned as the key to classifying, preserving, and interpreting a body of ancient knowledge; the author not only served as a foundation upon which different elements of knowledge were brought together, but also furnished cues to the interpretation of composite texts and thus created a notional coherence in texts. On a deeper level, the inquiry of early Chinese authorship also sheds light on the ritual, religious, and sociopolitical contexts influencing authorial attributions and on how such attributions are associated with early Chinese intellectual history in general.

I argue in Chapter One that the figure of the Yellow Emperor was forged out of the Eastern Zhou ritual and religious thought that bears the mark of the ancestral veneration of high antiquity while at the same time reflecting the concerns of the changing social realities of the time.

I argue in Chapter Two that the written materials later incorporated into the Lunyu originally served different purposes and were interpreted differently in different contexts. The compilation of the Lunyu in the early Western Han was concomitant with the trend of elevating and mythiciz- 
ing Confucius as the creator of the Han governmental ideology because he filled the need for a tangible, quotable authority.

Chapter Three argues that the "Yaolüe," the last chapter of the extant Huainanzi, was composed after Liu An's death as the means to impart a cohesive unity to the writings left from Liu An's Huainan court. It further explores the relationship between the patron-author and the actual writers or compilers.

In Chapter Four I argue that neither of the two documents is an autobiographical account written by Sima Qian. Instead, the voice of frustration conveyed in these two sources should be understood as the collective voice of the Han intellectuals.

In Chapter Five I suggest that in the study of early Chinese translations of Buddhist texts we cannot view early catalogues of Buddhist translations as historical records; instead, we need to explore why and under what circumstances those catalogues were compiled. The intention of differentiating "true," "authentic" translations from apocryphal sutras was one of the most important factors motivating the cataloguing of early translated Buddhist scriptures. 